\title{
Resource utilization of financially disadvantaged kidney transplant recipients
}

\author{
Ana Mae H. Quintal- Quetua ${ }^{1}$, Roy Diamond Arco ${ }^{1}$ and Romina A. Danguilan ${ }^{1 *}$ \\ ${ }^{1}$ Department of Adult Nephrology, National Kidney and Transplant Institute, East Avenue, Diliman, Quezon City, Philippines
}

\begin{abstract}
Background: The financial cost of maintaining a transplant recipient is substantially less than that of hemodialysis (HD). The study aimed to identify the different resources utilized by the end stage renal disease (ESRD) patients for kidney transplantation (KT), to determine the employment rate and family monthly income of ESRD patients, and to determine the percentage of ESRD patients who were transplanted 1 year from the time of the study period.
\end{abstract}

Methods: This is a retrospective cohort study reviewing the charts of all new ESRD patients aged more than 18 years, accepted by Medical Social Service Division (MSSD) for kidney transplant program from January 1, 2010 to December 31, 2010 at the National Kidney and Transplant Institute (NKTI).

Results: A total of 588 ESRD patients $>18$ years of age were included from January 1, 2010 to December 31, 2010. A total of 30 out of the 49 (61\%) KT enrollees were transplanted. The following were noted among the transplanted patients in contrast to those who were not transplanted: they had a higher monthly family income of $>$ US $\$$ 575 ( $40 \%$ versus $21 \%$ ), higher proportion of support from family member with retirement benefits/ pensions (17\% versus 5\%), higher proportion who received contributions from government officials ( $23 \%$ versus $5 \%$ ) and country's national lottery (10\% versus $2 \%$ ) and higher proportion of overseas support (40\% versus $21 \%)$.

Conclusion: Patient's total family income, support from family members and relatives, overseas support, and acquisition of external funding from dictate whether a patient can sustain the transplant work- up and be transplanted.

\section{Introduction}

The financial cost of maintaining a transplant recipient is substantially less than the alternative forms of renal replacement therapy [1]. A study on health financing noted that Filipinos' out-of-pocket expense for health care has increased from 45 percent in 1998 to 54 percent in 2007. This means that for every P1, 000 (\$23) spent on health care, families shoulder more than half or P540 (\$13). The Philippine Health Insurance Corporation (Philhealth), the Philippine's national health insurance, contributes only P85 (\$2), while the rest comes from subsidies to hospitals by the national and local governments [2].

In National Kidney and Transplant Institute (NKTI), the Philippines' tertiary renal care hospital, economically disadvantaged patients with end stage renal disease (ESRD) are referred to Medical Social Service Department (MSSD) for assistance. The MSSD set the guidelines for giving discounts on hospital charges.

The study aimed to determine the employment rate and family monthly income of ESRD patients, to identify the different resources utilized by the ESRD patients for kidney transplantation, and to determine the percentage of ESRD patients who were transplanted 1 year from the time of the study period. This information can guide the government to make policies on how to assist patients through Philhealth and may be used by NKTI as basis to increase government subsidy for service patients so that KT can be offered to all ESRD patients.

\section{Materials and methods}

This is a retrospective cohort study reviewing the charts of all new ESRD patients aged more than 18 years, accepted by MSSD for kidney transplant program from January 1, 2010 to December 31, 2010 and non NKTI ESRD patients who were referred to MSSD for kidney transplantation during the study period.

\section{Results}

There were 919 patients who met the inclusion criteria. There were 331 patients who were lost to follow up. There were 106 patients who opted for conservative treatment, 460 started either HD or PD, and 49 were enrolled to KT program.

Among the 49 patients enrolled in the KT program, only 30 (61\%) were transplanted in 1 year. Seven percent were transplanted on time but majority (80\%) had delayed transplant; 13\% (3/24) of those with delayed KT had donor- related problems. Thirteen percent were transplanted more than 12 months from the time of start of work- up.

\section{Demographic data}

Patients had the same male to female ratio and mostly were married. Chronic glomerulonephritis was the most common etiology of ESRD. The KT enrollees came from a younger age group of 31- 40 years old, $43 \%$ had no identified comorbidities, $47 \%$ were able to attain a college degree, had a higher rate of employment (51\%) and most (33\%) had a total family income of $>$ US $\$ 575$. The Dialysis and Conservative groups were noted to be older (41-60 years old), few had a college degree (17\% and $9 \%$, respectively), and most had at least 1 comorbid illness $(43 \%$ and $45 \%$, respectively).

Correspondence to: Romina A. Danguilan, Chair of the Department of Adult Nephrology, National Kidney and Transplant Institute, East Avenue, Diliman, 1101 Quezon City, Philippines, Tel: 6329810300, Fax: 6329810368, E-mail: dr.radanguilan@gmail.com

Received: March 09, 2017; Accepted: April 05, 2017; Published: April 07, 2017 
Patients from the Dialysis and Conservative groups likewise had a higher rate of unemployment (66\% and $80 \%$, respectively) and had a monthly family income less than US $\$ 115$ (32\% and 40\%, respectively). All three groups had a household member of 3-5. The 33\% of the KT group had the highest monthly family income (US\$ $>575$ ).

Compared to the Dialysis and Conservative groups, the following differences were noted among the KT enrollees: they had a higher percentage of the national health insurance (Philhealth) enrollment ( $88 \%$ versus $49 \%$ and $48 \%$, respectively), higher number of support from an overseas worker (32\% versus $7 \%$ in the dialysis group; the Conservative group had no overseas support), higher number of relatives providing financial support (55\% versus $38 \%$ and $15 \%$, respectively) and had a higher proportion receiving PCSO support (5\% versus $1 \%$ in both Dialysis and Conservative groups).

A total of 30 out of the $49(61 \%)$ KT enrollees were transplanted. In contrast to those who were not transplanted, the following were noted among the transplanted patients: they had a higher monthly family income of $>$ US $\$ 575$ ( $40 \%$ versus $21 \%$ ), higher proportion of support from family member with retirement benefits/ pensions (17\% versus $5 \%)$, higher proportion who received contributions from government officials (23\% versus $5 \%)$ and PCSO (10\% versus $2 \%)$ and higher proportion of overseas support ( $40 \%$ versus $21 \%$ ).

\section{Discussion}

Improving access to KT remains a persistent challenge, as the underlying burden of both chronic kidney disease and ESRD has continued to grow over the past decade. In the annual report of the Philippine Renal Disease Registry (PRDR), the number of new dialysis patients has increased by 73\%, from 5,621 in 2005 to 9,716 in 2010. The PRDR reports that a total of $399 \mathrm{KT}$ were done nationwide, among these, $257 \mathrm{KT}$ were done at the NKTI alone in 2010 and 254 in 2011. Among the financially disadvantaged ESRD population in NKTI, only $82(32 \%)$ were transplanted in 2010 and 87(34\%) in 2011 [3].

Sixty percent of all treated ESRD patients are treated in European Union nations, the United States and Japan. [4] with the developed world accounting for more than $90 \%$ of transplants worldwide $[5,6]$. By comparison, Japan, Philippines and Taiwan had a kidney transplantation rate of $<25$ new transplants pmp [7].

In $2010,64 \%$ (257/399) of the total number of transplants were performed in our Institution, and only 32\% (82/ 257) were service patients, whose treatment was subsidized by the Institute. Among the 49 patients, $61 \%$ were transplanted within 1 year and the rest have not yet been transplanted until the present time. Some of the following reasons were: $32 \%$ had donors rejected while others did not return for follow-up. Financial constraints probably remain the main reason they did not complete the work-up.

In India, the cost of KT varies from $\$ 1,500$ in government hospitals to as high as $\$ 7,000$ in private institutions [8]. In Indonesia KT cost is higher, approximately $\$ 15,000$ [9]. In our Institution, Orejudos, et al. reported that the mean cost of successful pre- KT work- up was P203,397 $(\$ 4,770)$ and in those with failed pre- KT work-up, the mean expenditure after 1 year was P336,680 (\$7,900) [9]. This explains the economic difficulties patients face even with the expenses required for pre-transplant evaluation.

Government subsidy for health related problems is very minimal in this country. Only 3.8\% of the country's GDP is allotted for health [2] and the Philhealth subsidizes only P69, $000(\$ 1,619)$ for the transplant operation itself. Given such huge expenses and limited funding by the government, it seems obvious why there is a limited number of ESRD patients enrolled in the transplant program. The expenses incurred from lifelong dialysis however are higher; therefore patients are still encouraged to proceed with transplantation.

Individual sourcing of funds, exploring assistance from various family ties indeed plays an important role in the Philippines, in contrast to a study from one Indian transplant center that organized external parties (government and NGO together) to fund poor patients, rather than rely on an individual's resources. The cost for transplantation of their poor patients came largely from employers and various charitable institutions [7].

In Pakistan, the government finances only about $40 \%$ of the cost for transplantation and the rest is derived from the community as donations. In addition immunosuppressants were given free to all KT patients [5]. In our setting, the MSSD encourages all patients to secure additional funding from the PCSO for their post- transplant maintenance drugs. It would benefit them greatly if there were also more charitable institutions that can assist in supporting their medications after transplantation.

Government together with industry, private and charitable organizations need to work together to provide RRT at a cost that the government can afford. This is the only way treatment can be started for all patients diagnosed with ESRD.

\section{Conclusion}

ESRD patients still shoulder most of the expenses in RRT with only minimal government subsidy. Despite the maximum financial assistance provided to service patients by the Institute, very few get transplanted. Those who found other means of income or additional funds after their initial diagnosis were more likely to be enrolled to the transplant program. Patient's total family income, support from family members and relatives, overseas support, and acquisition of external funding from both governmental and NGOs dictate whether a patient can sustain the transplant work- up and eventually get transplanted.

\section{Conflict of interest statement}

I currently have, or have in the past two years, an affiliation with:

1. Consulting fees: No

2. Stock/allotment: No

3. Patent royalties / licensing fees: No

4. Honoraria (e.g. lecture fees): Yes

5. Fees for promotional materials: No

6. Research funding: Yes (Novartis, Dega)

7. Scholarship from corporation: No

8. Corporate laboratory funding: No

9. Others (e.g. trips, travel, or gifts): No

\section{References}

1. Vella JP, Carpenter CB (2000) Current results and determinants of graft outcome in kidney transplantation. In: Owen WF (Ed.) Dialysis and Transplantation- A companion to Brenner and Rector The Kidney, WB Saunders; Philadelphia: 499-510.

2. Vera L (2012) Truth is our business. 'Conservative' and 'sluggish' PhilHealth misses health care target. 
3. Philippine Renal Disease Registry (2010) PRDR Annual Report, Philippine Society of Nephrology and Renal Disease Control Program, National Kidney and Transplant Institute, Department of Health.

4. Alebiosu CO, Ayodele OE (2005) The global burden of chronic kidney disease and the way forward. Ethn Dis 15: 418-423. [Crossref]

5. Chevalier C, Busson M, Dupuy JM, Hors J, Foulon G (1991) Medical care of end-stage renal disease in 52 countries: evolution since 1975 and potential activity for the next 5 years. Transplant Proc 23: 2529-2530. [Crossref]
6. Wolfe RA, Ashby VB, Milford EL, Ojo AO, Ettenger RE, Agodoa LY, et al. Comparison of mortality in all patients on dialysis, patients on dialysis awaiting transplantation, and recipients of a first cadaveric transplant. NEng J Med 341: 1725-1730.

7. Kher V (2002) End-stage renal disease in developing countries. Kidney Int 62: 350362. [Crossref]

8. Bennett PN, Hany A (2009) Barriers to kidney transplants in Indonesia: a literature review, International nursing review. 56: 41-49.

9. Orejudos, R, Tan, E, Padilla B (2005) A study on the Process of Evaluating Kidney Transplant Candidates among Indigent Patients at NKTI. NKTI Proceedings. 7: pp 99.

Copyright: (2017 Quintal-Quetua AMH. This is an open-access article distributed under the terms of the Creative Commons Attribution License, which permits unrestricted use, distribution, and reproduction in any medium, provided the original author and source are credited. 